\title{
A Experiência do Tempo em Merleau-Ponty: Contribuições para a Fenomenologia Clínica
}

\author{
Anna Karynne Melo \\ Universidade de Fortaleza \\ Vitor Vasconcelos de Araújo \\ Pontificia Universidade Católica do Rio Grande do Sul \\ Lucas Bloc \\ Universidade de Fortaleza \\ Virginia Moreira \\ Universidade de Fortaleza
}

\begin{abstract}
RESUMO
A experiência do tempo é uma noção central na fenomenologia filosófica e clínica. $O$ tempo na fenomenologia de Merleau-Ponty é uma experiência mundana, subjetiva e inseparável do sujeito. $\mathrm{O}$ filósofo entende a vivência do tempo como uma rede de intencionalidades e não como uma sequência estrutural que se ultrapassa a si mesma. Este artigo descreve a experiência do tempo no pensamento de Merleau-Ponty como possível contribuição para a fenomenologia clínica. O tempo é a tensão dialética entre o passado e o futuro, que só se supera na medida em que, conjuntamente, se conserva, ou ainda, é a ambiguidade entre o retencional e o sucessivo. Propomos a noção de experiência do tempo como processo ambíguo como contribuição para a fenomenologia clínica.
\end{abstract}

Palavras-chave: Experiência; Merleau-Ponty; Fenomenologia; Tempo; Fenomenologia Clínica.

\begin{abstract}
Time experience in Merleau-Ponty: contribuitions for clinic phenomenology

This article describes the experience of time in the thought of Merleau-Ponty as a possible contribution to the phenomenological clinic. Merleau-Ponty compares the experience of time with a network of intentionalities. In this sense, he departs from the notion of a structural sequence that surpasses itself. Time is the product of a dialectical tension between past and future, who is only overcomed by itself in as much as, jointly, preserves itself. It an also be understood as an ambiguity between the retentional and the successive. Thus, we propose to bring the idea of time as an ambiguous process to the psychological clinic, in a contribution to the humanisticphenomenological approach. This is so because, characterized by experiential ground, it makes use both of existentialist and phenomenological tradition.
\end{abstract}

Keywords: Experience; Merleau-Ponty; Phenomenology; Time; Clinic Phenomenology.

A experiência do tempo ocupa um lugar central nas fenomenologias filosófica e clínica. Para MerleauPonty, que dialoga e critica frequentemente Husserl em seu percurso, as reflexões sobre o tempo se configuram como um eixo primordial de sua filosofia (Barbaras, 2001). Quando discute a noção do tempo, MerleauPonty destaca sua dimensão mundana e subjetiva. Trata-se de um tempo que "pertence invisivelmente ao mundo e à subjetividade" (Dupond, 2008, p. 205). O tempo não é visto como coisa ou substância fluida, mas em seu caráter inseparável do sujeito com uma dinâmica própria. Para Merleau-Ponty (1945/2006), há uma dimensão temporal assumida ou vivida pela subjetividade e que se confunde com a coesão da vida.
Ao realizar a releitura do pensamento de Husserl, Merleau-Ponty (1945/2006), já no prefácio da Fenomenologia da Percepção, defende a ideia de uma fenomenologia transcendental articulada a uma filosofia da existência. Para Merleau-Ponty (1945/2006), o caminho da gênese da subjetividade transcendental não permite a produção de uma experiência de sobrevoo. A facticidade do sujeito do conhecimento e seus posicionamentos espaciais e temporais não são seu momento negativo a ser superado por um princípio racional englobante, mas um caminho ininterrupto de apropriação da subjetividade de si mesma.

A crítica feita por Merleau-Ponty acerca da distin- 
ção cartesiana entre psicologia empírica e psicologia racional, no pensamento husserliano (Merleau-Ponty, 2006), torna descartável a distinção entre as intuições do eu empírico e a experiência transcendental do eu. Para o filósofo francês, toda experiência já é uma compreensão, mesmo que precária, da experiência transcendental. Por isso, não são poucas as referências de Merleau-Ponty à experiência cotidiana e mesmo às experiências científicas, principalmente aquelas da psicologia, para dar conta do objetivo de refutar as falácias dedutivas da filosofia da consciência e do reducionismo objetivista.

Este cenário epistemológico inaugurado por Husserl e, posteriormente, ocupado por filósofos como Martin Heidegger, Jean-Paul Sartre, Maurice Merleau-Ponty, dentre outros, representa, na fenomenologia filosófica, uma contribuição importante na criação de uma renovação ontológica e, por conseguinte, metodológica dentro do campo de saber da psicologia, da psicoterapia e da psiquiatria, entendidos aqui como vias possíveis de uma fenomenologia clínica. Assim, podemos dizer que, a partir do início dos anos 1920, o debate iniciado pela fenomenologia filosófica transbordou o campo da filosofia e os trabalhos de psiquiatras como Minkowski, Binswanger, Boss, Strauss, Ey e Von Gebsattel foram pioneiros na exploração de uma clínica inspirada pela fenomenologia. Houve um desejo destes psiquiatras em dialogar com a filosofia (Dastur, 2014) que abriu o caminho para diversas possibilidades de uma perspectiva clínica da fenomenologia.

Originariamente concebida como uma forma de abordar os transtornos mentais, diversas denominações foram utilizadas: fenomenologia psiquiátrica, psicopatologia fenomenológica, análise fenômeno-estrutural, análise existencial, Daseinsanálise, antropologia fenomenológica das psicoses et fenomenologia clínica (Charbonneau, 2010). Ainda que existam diferenças nestas vias, encontramos como ponto comum a fenomenologia como base epistemológica e via de implicação do movimento clínico. Optamos por utilizar o termo fenomenologia clínica em função de sua amplitude e capacidade de dar conta tanto da clínica psiquiátrica como psicológica, quanto dos possíveis modelos de psicoterapia de natureza fenomenológica. Quando falamos de fenomenologia clínica estamos nos referindo à psiquiatria, à psicologia clínica e à psicoterapia como intervenções terapêuticas em psicopatologia. A fenomenologia clinica se constrói no discurso teórico da psicopatologia sustentada, desde seu início, pelo contato clínico e pelas densas referências da fenomenologia filosófica, entre elas, sobre a de experiência do tempo. Trata-se de uma noção central, não só para a elaboração da reformulação da tradição filosófica, como também fornece ao fenomenólogo clínico, seja ele psiquiatra ou psicólogo clínico, um conjunto descritivo das disposições estruturais de processos subjetivos e se apresenta como nodal na tradição das abordagens fenomenológicas em psicoterapia.

No tradição da psicopatologia fenomenológica, campo fundamental na fenomenologia clínica, encontramos estudos clássicos sobre a experiência do tempo, ou o tempo vivido (Binswanger, 1960/2005, Minkoswki, 1933/1955, Strauss, 1968/2000, Tatossian, 1997/2014). Os primeiros trabalhos desenvolvidos no lastro da fenomenologia clínica, propostos por Minkowski e Binswanger, utilizavam a discussão do tempo na compreensão, principalmente, da melancolia; uma marca dos primeiros trabalhos no surgimento da psicopatologia fenomenológica. É, então, importante o aprofundamento deste conceito fundamental para toda e qualquer clínica que se proponha a ser fenomenológica.

Partindo do pressuposto da fecundidade e potência da fenomenologia de Merleau-Ponty no âmbito da clínica (Bimbenet, 2011), este artigo tem como objetivo, inicialmente, apresentar a noção de experiência em seu pensamento, mais especificamente, a experiência de tempo, apontando, em sua filosofia, o reconhecimento de um alcance inédito à ideia da passagem temporal. Neste sentido, elaboramos cinco eixos de discussão: a noção de experiência como forma, a ideia de tempo como sucessão, a experiência do corpo próprio como tempo, o tempo como a tensão entre o sucessivo e o retencional e a dimensão ambígua da experiência do tempo em Merleau-Ponty. Por último, discutimos as possíveis contribuições desta noção para a fenomenologia clínica que, embora adentre largamente nesta discussão, principalmente através das obras de Husserl e Heidegger, muito pode se beneficiar da fenomenologia de Merleau-Ponty (Tatossian \& Moreira, 2012; Moreira, 2009 e 2007).

Neste artigo restringimos nosso escopo de discussão ao período de teses de Merleau-Ponty, focando em seus dois primeiros trabalhos, A estrutura do comportamento (1942/2006) e a Fenomenologia da percepção (1945/2006). Nestas obras Merleau-Ponty apresenta uma nova definição da experiência do tempo. Nossa escolha se fundamenta no esforço do primeiro MerleauPonty em rearticular a problemática transcendental, devolvendo às filosofias da consciência a ligação com os fenômenos da realidade. Dessa maneira, a diferença entre a filosofia transcendental e a psicologia não é 
mais de uma distinção abismal feita pela filosofia clássica, mas se dá somente a partir dos níveis de aclaramento da experiência perceptiva. Enquanto esta é uma compreensão inicial da dimensão universal da experiência psicológica, aquela nos oferece um percurso mais formalizado da subjetividade transcendental (MerleauPonty, 1964), embora ambas conservem a verdade do mundo percebido.

\section{EXPERIÊNCIA DO TEMPO ENQUANTO FORMA}

Em A estrutura do comportamento, Merleau-Ponty, a partir da investigação de discordâncias internas da teoria do arco-reflexo e do reflexo condicionado, busca a compreensão do comportamento como uma esfera dinâmica e integrada. O filósofo busca, nesta obra, compreender o "comportamento humano como uma totalidade em que cada parte só tem sentido quando atuando em conjunto com as demais" (Coelho Jr. \& Carmo, 1991, p.41).

Visando esta finalidade, o pensador francês apropria-se da noção de forma da psicologia da Gestalt, por compreender que ela contém importantes críticas às pressuposições atomistas e realistas da psicologia clássica. A ideia de forma, ou estrutura, é definida como um "conjunto de forças em estado de equilíbrio ou de mudança constante, de forma que nenhuma lei seja formulável para cada parte isolada e que cada vetor seja determinado em grandeza e direção por todos os outros" (Merleau-Ponty, 1942/2006, p. 213). Em outras palavras, a totalidade de um fenômeno comportamental é qualitativamente distinta da soma algébrica de seus elementos constituintes.

A alternativa oferecida pela psicologia da Gestalt é a de um modelo compreensivo distinto acerca da relação entre organismo e meio. A interação mecanicista cede espaço para outra concepção de causa, já que as propriedades dos elementos particulares envolvidos na causalidade do comportamento são menores do que a forma geral da conduta emitida pelo organismo (Merleau-Ponty, 1942/2006).

O filósofo francês indica, portanto, que os seres vivos, "reagem de uma maneira adaptada ao espaço, mesmo na ausência de estímulos atuais ou de estímulos recentes que sejam adequados" (Merleau-Ponty, $1942 / 2006$, p. 41). Merleau-Ponty (1942/2006) ao contrapor os organismos como entes passivos regidos por leis das quais não possuem o sentido, rejeita os critérios objetivos da empiria psicológica, pois segundo esta, o comportamento é apenas um conjunto de vetores determinados e localmente posicionados.
Essa compreensão mecânica da qualidade dos comportamentos se depara com um limite diante das pesquisas da fisiologia contemporânea, quando renovaram o estudo da vida a partir de um princípio dinâmico, vivo e organizado. Elas tiveram um impacto profundo não só na psicologia experimental, mas no legado filosófico clássico, atribuindo um valor negativo às filosofias da consciência e ao empirismo quando ressaltaram complexos sistemas de correlações, seja de regulações endócrinas seja, sobretudo, no reconhecimento de coordenações sensitivo-motoras (Merleau-Ponty, 1942/2006). Por isso, para Merleau-Ponty, os organismos são considerados cada vez menos passivamente dependentes do meio de vida e cada vez mais aptos a construírem um meio para seus elementos, ao passo que o meio faz, retroativamente, desses elementos um organismo.

A psicologia da Gestalt serviu a Merleau-Ponty não só para sustentar a argumentação de que o reflexo puro era um impasse heurístico com relação aos achados experimentais, mas também para afirmar que a teoria da reflexologia clássica poderia apenas dar conta de comportamentos patológicos. Merleau-Ponty irá utilizar-se também dos relatos clínicos da psicopatologia psiquiátrica da neuropsiquiatria alemã de Adhémar Gelb e Kurt Goldstein. Ambos os autores irão afirmar que o que se encontra perdido nos pacientes psiquiátricos não é a capacidade de associação de estímulos, ou de realização do mecanismo descrito pela psicologia empírica, mas a coordenação de atividades que permite ao sujeito realizar não só seus objetivos vitais, mas criar estratégias para driblar impasses exteriores, conservando a funcionalidade de uma ação.

A perda do aspecto virtual poderia ser resumida na inabilidade de emancipação do mundo, ou ainda, um encolhimento da liberdade do paciente e uma adesão maior às exigências de seu entorno. Em outras palavras, o sujeito perde a capacidade de lidar com aquilo que não é real (Goldstein, 1995), uma vez que o comportamento sadio é composto não só de atualidades materiais, mas também de uma potência para realização de condutas que não se encontram determinadas pela situação presente.

Para que um comportamento seja funcional, é preciso, portanto, que ele não seja apenas construído a partir dos vetores atuais que tornam possíveis sua ação. Eles devem conter novos índices espaciais e temporais para que os comportamentos não sejam apenas uma repetição de um mecanismo cego.

Merleau-Ponty insiste, tomando como base essas 
considerações da psicologia da Gestalt, que, longe de serem lidos como realidades atômicas, os comportamentos devem ser considerados a partir de sua distribuição no tempo, sua sequência melódica e de acordo com "as relações de grandeza dos objetos; em geral: [de acordo com] a estrutura precisa da situação" (MerleauPonty, 1942/2006, p.84). Por isso, os rearranjos comportamentais devem ser compreendidos para além de fatos isolados, mas como uma articulação com o conjunto espacial e temporal que motivam a reorganização funcional. Assim, a ordenação do comportamento no tempo e no espaço são variáveis tão determinantes quanto as próprias interações dos elementos físicos na produção do comportamento organizado.

\section{EXPERIÊNCIA HUMANA DO TEMPO COMO SUCESSÃO}

De acordo com Merleau-Ponty, para os psicólogos da Gestalt, "minha consciência é uma forma mais integrada que esta lâmpada, mas não passa de uma forma" (Merleau-Ponty, 1973, p. 31). Mas devemos percorrer o caminho inverso ao da psicologia da Gestalt: ao invés de supor que existe uma realidade física, parte de uma infraestrutura integrada, que opera através de funções distributivas, que apresenta um funcionamento correlativo, e, por sua vez, que oferece condições materiais para uma realidade mais complexa - a da percepção -, devemos entender que "[s]omente podemos conhecer a fisiologia viva do sistema nervoso partindo dos dados fenomenais" (Merleau-Ponty, 1942/2006, p. 139). É a percepção, em sua realidade fenomenológica, que fornece a ocasião de conceber as formas inteligíveis da fisiologia dinâmica e as totalidades organizadas dos sistemas físicos.

Assim, a Gestalt é tida, ambiguamente, tanto como uma dimensão fenomênica, como um objeto de conhecimento, por apresentar "uma relação não causal entre consciência e meio [...] que engloba toda a amplitude dos fenômenos reconhecidos como gestálticos" (Ferraz, 2006, p. 36).

Com efeito, o eco que os dados fenomenológicos fazem com os outros animais e com o desenrolar de eventos de realidades físicas não fazem do primeiro o princípio de inteligibilidade do segundo, mas ao contrário: é porque as realidades objetivas (em-si) e os comportamentos animais ou de outrem fornecem ao sujeito (para-si) intuições gestálticas que podemos fazer delas uma forma geral da experiência perceptiva.

A amplitude fenomênica das realidades gestálticas deve obedecer a uma gradação estrutural e não causal.
Isto é, não é a realidade física que causa uma realidade vital e que, por sua vez, causa a produção consciente de intuições autorganizadas, mas, ao contrário, é porque o sujeito percebe intuições globais dos objetos que podemos fazer do sentido gestáltico uma maneira geral de disposição dos objetos do mundo.

Essa gradação estrutural significa dizer que em todo o universo das formas estão presentes "caracteres 'dominantes' na matéria, na vida ou no espírito" (MerleauPonty, 1942/2006, p. 207). Como já vimos anteriormente, os níveis da vida e do espírito não são compostos pela somatória algébrica de processos reais, mas por uma nova disposição estrutural, irredutível aos níveis de organização aceitos pelo realismo. A forma vital é o surgimento de uma organização qualitativamente distinta do físico e o psíquico, ou humano, é uma forma qualitativamente distinta da normatividade vital dos animais.

Por conseguinte, dirá Merleau-Ponty (1942/2006), "a forma é, pois, não uma realidade física, mas um objeto de percepção, sem o qual, aliás, a ciência física não teria sentido, já que é construída em função dele e para coordená-lo" (p. 224).

Por sua vez, a diferença qualitativa da experiência humana consiste não só na sua autorganização e na capacidade de estabelecer para si uma grande amplitude comportamental, mas no reconhecimento da presença de outrem nas ações de seus próprios projetos históri$\cos -\mathrm{o}$ que atesta, portanto, sua realidade intersubjetiva. Isto é, primeiramente os homens captam realidades marcadas pela necessidade de reconhecimento social, para, em seguida, de posse dessa dimensão primeva, serem capazes de perceber formas vitais, posteriormente captando as leis de um sistema físico.

Para Merleau-Ponty (1942/2006), a especificidade das ações humanas caracterizadas como comportamento simbólico, é uma trajetória sucessiva que se supera a cada momento de sua passagem. O símbolo é a capacidade de destacar-se tão radicalmente de uma situação atual a ponto de ser capaz de elaborar sentidos novos que surpreendem as sedimentações de significado que o precederam. De forma sintética, Bimbenet (2011) afirma que o comportamento simbólico humano é a transformação interior das funções biológicas produzindo uma integração inteiramente nova.

O "significado humano é dado antes dos pretensos signos sensíveis" (Merleau-Ponty, 1942/2006, p. 260), pela ocasião de que a intersubjetividade representa a realidade privilegiada da consciência dos homens, pois as situações que fazemos nossas são feitas a partir da 
dimensão do trabalho de outrem. Esta consciência mais ou menos pura do outro é a ocasião na qual é possível que utensílios humanos sejam mais do que o reconhecimento de sua função presente, mas a superação constante de suas finalidades.

Por isso, Merleau-Ponty (1942/2006) nos esclarece que,

o que define o homem não é a capacidade de criar uma segunda natureza - econômica, social, cultural - para além da natureza biológica, é sobretudo a capacidade de superar as estruturas criadas para criar outras (p. 273, grifos nossos).

De modo que toda a disposição estrutural do comportamento humano é uma organização de qualquer conduta em profundidade, em que um modo de comportamento passado não possui mais lugar no sentido presente, "ela alcançaria um comportamento perfeitamente integrado, cada momento da qual seria interiormente interligado ao conjunto" (Merleau-Ponty, 1942/2006, p. 276), uma vez que o tempo da história humana apaga os vestígios de vivências ancestrais, dando a ela um significado inteiramente novo.

Assim, a vida adulta deve ser a compreensão dos impasses vividos nos desacordos e conflitos da vida infantil, uma vez que o tempo aqui é discutido de maneira inteiramente sucessiva, isto é, a esfera da passagem nada mais é do que o "um após o outro". Em MerleauPonty (1942/2006) "seria preciso considerar o desenvolvimento, não como a fixação de uma força dada em objetos dados também fora dela, mas como uma estruturação progressiva e descontínua do comportamento" (p. 276).

A lógica do tempo, portanto, é a de realizar uma superação de si a si, impulsionando a experiência para etapas do desenvolvimento que não tem lugar em vivências transcorridas. Dito de outra forma, o tempo é uma instância inteiramente negativa, capaz de superar tudo aquilo que se deu em um estágio anterior da linearidade, sem deixar cicatrizes ou vestígios. O significado humano sadio é um trabalho de elaboração de um comportamento que ultrapassa (dépasse) a si mesmo, ao longo de um tempo e um espaço indefinidos (Dorfman, 2007).

\section{EXPERIÊNCIA DO CORPO PRÓPRIO COMO TEMPO}

Em sua obra mais famosa, Fenomenologia da percepção, Merleau-Ponty (1945/2006), inicia uma segunda tentativa de construir um fundamento universal da subjetividade humana. Muito embora unidas por uma cumplicidade teórica, qual seja, a tentativa de articula- ção entre ideia e matéria, há uma distinção metodológica entre $A$ estrutura do comportamento $\mathrm{e}$ a Fenomenologia da percepção que denota um impacto expressivo no tratamento da noção da experiência do tempo.

O novo procedimento metodológico, a époche, diverge à tomada da experiência científica como o caminho para a chegada a uma experiência transcendental, tal como Merleau-Ponty fizera na obra de 1942 (Waelhens, 2006). Na obra magna de 1945, à sombra do pensamento de Husserl, a filosofia deveria se beneficiar "de um trabalho já feito, de uma síntese geral constituída de uma vez por todas" (Merleau-Ponty 1945/2006, p. 319). Significa dizer que os fundamentos transcendentais do sujeito perceptivo já estão implicitamente presentes nas atitudes cotidianas e na ciência, embora precisem de um movimento que inverta a ordem natural da percepção, de modo a forçar a experiência transcendental para fora de seu ocultamento e chegar, assim, na sua autoapresentação (Oliveira, 2012).

Por isso, não se trata mais de apoiar-se nas discordâncias internas das teorias materialistas e intelectualistas, mas de passar a palavra para o próprio sujeito perceptivo, no qual repousa uma compreensão insuficiente dos processos psicológicos através das objetivações da ciência moderna. É preciso tornar o objeto da ciência psicológica um sujeito e permitir que ele produza seus próprios princípios, saindo, assim, do ocultamento a partir do qual fora encoberto pelas teorias reducionistas e pelas falácias dedutivas da filosofia transcendental usual.

Desse modo,

todo o universo da ciência é construído sobre o mundo vivido, e se queremos pensar a própria ciência com rigor, apreciar exatamente seu sentido e seu alcance, precisamos primeiro despertar essa experiência do mundo da qual ela é a expressão segunda. (Merleau-Ponty, $1945 / 2006$, p. 3)

Husserl participa da discussão de Merleau-Ponty não só a partir da utilização de um instrumental metodológico distinto daquele reconhecido em sua primeira obra, mas adentra também, e de maneira muito importante, na redefinição da noção de experiência temporal. Aqui, Merleau-Ponty poderá dizer mais do corpo humano do que uma forma de existência intersubjetiva capaz de realizar uma abstração de dados concretos, distanciando-se, dessa forma, da realidade imediata. O corpo não só pode ter uma posse indivisa de si mesmo, mas também pode produzir uma maneira de refletir sobre si mesmo. A reflexão não é um ato intelectivo. $\mathrm{Na}$ 
verdade, as faculdades judicativas da consciência humana somente podem derivar de uma experiência da reflexividade sensível. Podemos dizer ainda, que o corpo vivido se qualifica como infraestrutura intencional capaz de sentir a própria sensibilidade.

Exatamente por isso, por colocar-se no limiar da distância e da aproximação do objeto e de si mesmo, o corpo próprio possui uma relação não só com eventos concretos, mas também com situações futuras ou imaginárias.

\section{Merleau-Ponty nos dirá que o corpo vivo}

é reconhecível pelo fato de me dar "sensações duplas": quando toco minha mão direita com a mão esquerda, o objeto mão direita tem esta singular propriedade de sentir, ele também. [...] as duas mãos nunca são ao mesmo tempo tocadas e tocantes uma em relação à outra. Quando pressiono minhas mãos uma contra a outra, não se trata então de duas sensações que eu sentiria em conjunto, como se percebem dois objetos justapostos, mas de uma organização ambígua em que as duas mãos podem alternar-se na função de "tocante" e de "tocada" (Merleau-Ponty, 1945/2006, p. 137).

A categoria da reversibilidade - a capacidade do corpo próprio, ou corpo sujeito, de alternar as posições livremente entre sujeito e objeto - apresenta a particular característica de substituir o processo da reflexão como pertencente a uma esfera reflexiva da consciência constituinte e indica, a partir da epoché, um processo ambíguo que se desenreda entre a distância e a aproximação do sujeito ante o espetáculo sensível. Dessa forma, o corpo vivo é ao mesmo tempo um naturante e um naturado, ou ainda, uma estrutura viva e ao mesmo tempo um produtor de conceitos. De acordo com Moura (2008), a simultaneidade desse processo, que se aproxima e se distancia do objeto, é de natureza não identitária, uma vez que o corpo próprio se descobre não só voltando a si, mas também se reconhecendo naquilo que lhe é estranho.

A reversibilidade sensível está fundada em uma ideia robusta de temporalidade, pois, em vez de os fatos sucederem no interior do Ser de maneira indiferente, eles se apresentam no corpo próprio como retenção e como projeção de eventos, constituindo o duplo horizonte temporal da experiência transcendental, dando à subjetividade uma orientação histórica. Tudo se passa como se o sujeito tomasse emprestado uma dimensão já-aí, que se renova em cada ato de fixação da montagem sensível, razão por que "a unidade do objeto aparece pelo tempo, e porque o tempo escapa a si na medida em que ele se retoma" (Merleau-Ponty, $1945 / 2006$, p. 322, grifo nosso).
Por razão de que o tempo nunca é a identificação consigo mesmo, o corpo próprio, ao tomar emprestadas as sínteses parciais da temporalidade, pode realizar também uma distanciação da realidade, projetando-se em situações nunca antes vividas, ou imaginando cenários nunca antes experienciados. Ele pode também retroceder a um passado longínquo, quase animal, ou passear, a partir de narrativas, em experiências já findadas. Segundo Merleau-Ponty (1945/2006), o tempo não é nem um processo real nem uma sucessão efetiva, ele tem como origem a relação do sujeito com as coisas cujo corpo tem um papel ativo. Nós carregamos no nosso corpo as significações dos vividos passados, mas que se apresentam apenas no presente. Existem relações temporais que são estabelecidas em nosso campo de presença. A subjetividade é temporalidade e fornece um passado ao presente e uma direção para o futuro. O vivido nos toca, estando presente e permanecendo sem cessar em nossa experiência. Não se vive fora do presente, mas aquilo que é vivido, a dimensão presente, tem o poder de penetrar no tempo e de buscar a eternidade em sua atmosfera temporal.

Podemos afirmar que, na clínica, o sujeito passeia em suas narrativas circunscritas no corpo e projetadas pelo próprio corpo. Uma clínica fenomenológica se centra sobre o presente, mas não de forma estática. Parte-se da compreensão que não há outra experiência que não seja aquela de presente. No entanto, nosso corpo carrega uma teia de significados, de experiências que nos constituem como sujeitos e que podem ser evocados. Constantemente, tais sentidos emergem na clínica e compõem a trama temporal que se tece ao longo de uma narrativa, seja evocando no presente aquilo que foi vivido, seja projetando, também no presente, um vir a ser. O tempo aparece sempre como fundo de toda experiência.

\section{EXPERIÊNCIA DO TEMPO COMO A TENSÃO ENTRE O SUCESSIVO E O RETENCIONAL}

$\mathrm{Na}$ Fenomenologia da percepção, Merleau-Ponty (1945/2006) trata de reconhecer que o tempo não é uma linearidade sucessiva, abandonando a utilização de uma gramática que privilegia as "estruturas perfeitamente integradas" da Gestaltpsychologie. De tal modo que o corpo próprio, no seu movimento de distância e aproximação dos objetos, é capaz de nos remeter a um padrão lógico do tempo, retomado ao longo de toda a obra de 1945 (Moura, 2008, Pinto, 2008, Leconte, 2012).

O tempo passado afunda no presente e tudo é visto através dos instantes temporais do agora. Mas o caráter 
transcorrido é indestrutível e transparece indefinidamente, não importam quantos instantes seguintes passem a recobri-lo. Assim, as vivências ancestrais são constantemente arrastadas adiante do presente. Este é como se fosse o núcleo do cometa, servindo como um ponto fonte para as projeções e antecipações dos instantes da experiência temporal do sujeito perceptivo. Por isto, "[...] esta apreensão do agora é, de algum modo, o núcleo para a cauda de cometa de retenções, respeitantes aos pontos-agora anteriores do movimento" (Husserl, 1994, p. 63).

Assim, o processo de rememoração é uma expansão da matéria do tempo. Dirá Husserl (1994) que esse caráter de dilatação faz parte da própria essência dos objetos temporais. Contudo, o dado retencional não é uma mera repetição de um instante passado e se dá de forma relativamente livre de seus pontos-fontes. $\mathrm{O}$ sujeito que relembra ou que re-presenta percorre livremente a linearidade do tempo objetivo, fazendo com que a presentificação ocorra mais depressa ou mais devagar, distinta ou confusamente.

A síntese que se produz pelos esboços que a consciência realiza dos momentos passados, trazendo-os ao presente, se torna, ela mesma, novos pontos-fontes, que servem, indefinidamente, para a produção de novos cometas, para insistir na analogia de Husserl. "A cada uma destas retenções agrega-se, então uma continuidade de mutações retencionais e esta continuidade é, ela própria, um novo ponto de actualidade, que se adumbra retencionalmente" (Husserl, 1994, p. 62). É essa a continuidade do tempo, a de permanecer como um fluxo constante de sínteses parciais que, por sua vez, impulsionam a formação de processos sintéticos que se seguem e que dão ao sujeito a experiência da mudança e da articulação dos instantes. Por isso,

Se Husserl introduziu a noção de retenção e disse que eu ainda tenho em mãos o passado imediato, foi justamente para exprimir que eu não ponho o passado ou não o construo a partir de um sombreamento (Abschattung) realmente distinto dele e por um ato expresso, que eu o alcanço em sua ecceidade recente e todavia já passada. (Merleau-Ponty, 1945/2006, p. 559)

Essa nova descrição da experiência temporal deve conter não só a forma bem sucedida das suplências funcionais das ações práticas dos sujeitos singulares, mas também a complexidade dos impasses afetivos da história humana quando articulam suas vivências passadas às suas experiências presentes, dando a elas uma forma, ou ainda, fazendo dela uma estrutura de sentido orientada (precariamente) para o futuro.

Assim, o velho experimenta sempre sua infância, uma vez que a vida precoce infantil não é mais um passado longínquo do qual o sujeito psicológico não tem mais condições de rememorar, mas uma perpétua retomada. "Aquilo que vivemos", dirá Merleau-Ponty, na Fenomenologia da percepção, "é e permanece perpetuamente para nós, o velho toca sua infância" (MerleauPonty, 1945/2006, p. 526). A apropriação do passado pode ser ora repetitiva, ora uma apropriação criativa dos impasses afetivos que se localizam na rede intencional de sua estrutura libidinal. Para Merleau-Ponty, a retomada do passado nem sempre se dá de forma inventiva e pode ser interpretada a partir de um circuito repetitivo sem abertura para o outro de si.

\section{UMA EXPERIÊNCIA AMBÍGUA DO TEMPO}

Para Merleau-Ponty (1945/2006), o tempo não se dá mais como uma série de "agoras", ou como puros atos. Ele assume que o eidos da experiência do tempo é exatamente a fabricação de totalidades parciais retomadas pelo sujeito a partir das solicitações com os objetos que despertam naquele um processo de rememoração de forma ininterrupta; cada presente reafirma a presença de todo o passado. Por esta razão,

(...) existe um só tempo que se confirma a si mesmo, que não pode trazer nada à existência sem já tê-lo fundado como presente e como passado por vir, e que se estabelece por um só movimento. (Merleau-Ponty, 1945/2006, p. 564)

Por isso, devemos reconhecer o nascimento da experiência humana singular a partir de uma ordem que a precede, qual seja, a dimensão da biologia animal e a experiência cultural. De um lado, um sentido cíclico e repetitivo e de outro uma generalidade intercambiável com as novidades que se oferecem ao sujeito motor, fazendo aparecer diante dele um mundo cultural. Assim, a experiência humana é um "conjunto de significações vividas que caminha para seu equilíbrio" (MerleauPonty, 1945/2006, p.212), mas uma forma de balanço sempre instável porquanto é capaz de dar a suas próprias vivências um novo nó de significações somente na medida em que se conserva.

Vemos aqui a insistência de Merleau-Ponty (1945/2006) ao reconhecer no homem a experiência da liberdade, assim como vimos a partir da corrosividade do comportamento simbólico, que se renova sem compromisso com o passado. Para Merleau-Ponty (1945/2006), o sujeito perceptivo apresenta um trânsito livre diante das condições de expressividade que o torna apto a diversificar suas ações, de maneira quase indefinida. A grande modalidade expressiva da 
linguagem articulada e da experiência artística evidencia o quão diverso podem ser a vivacidade da experiência humana. Contudo, ela deve apoiar-se na retenção de um passado no qual o sujeito não existia e em uma impessoalidade intersubjetiva para ser capaz de produzir a experiência da singularidade.

Caso ele seja incapaz de apoiar-se duplamente na esfera da vida e da cultura, o sujeito é apto a produzir apenas sentidos privados para uma consciência particular. Se o corpo próprio deseja criar uma experiência inventiva e comunicável, ele deve ser capaz de amparar-se em eventos gerais, de modo a produzir sentidos compartilháveis, porquanto a subjetividade é, ao mesmo tempo, uma efetividade natural e, ao mesmo tempo, uma manifestação cultural.

Se o sujeito humano é capaz de retomar as tensões internas do tempo, o espaço ambíguo entre o dado e o constituído, ele pode projetar-se diante de situações nunca antes vividas e produzir conceitos a partir dos quais formaliza sua experiência sensível. Assim, a intuição do tempo não é uma linha progressiva, mas uma rede de intencionalidades (Merleau-Ponty, 1945/2006).

Como anuncia Ricoeur (1997), a grande contribuição da fenomenologia acerca de suas meditações sobre o tempo é a de ampliar a ideia de sucessividade presente na estética transcendental de tradição crítica, incrustando nela o valor eidético da duração. Husserl, e ao a seu modo Merleau-Ponty, consideraram o tempo para além de uma linearidade temporal, e admitiram aquilo que Ricoeur (1997), citando o precursor da fenomenologia, chamará de o "grande agora".

É nesta noção de experiência do tempo, eminentemente ambígua, que entendemos a potencialidade do desenvolvimento da fenomenologia clínica, da psicoterapia, da clínica psicológica e psiquiátrica como um todo, tema fecundo para futuras pesquisas nesta área. $\mathrm{O}$ trabalho clínico inspirado na noção da experiência ambígua do tempo, para aquém de uma divisão entre consciente e inconsciente, interior e exterior, ou entre sujeito e objeto, busca contribuir para o desenvolvimento de uma clínica compreensiva do Lebenswelt.

\section{POSSÍVEIS CONTRIBUIÇÕES DA NOÇÃO DA EXPE- RIÊNCIA AMBÍGUA DO TEMPO PARA A FENOME- NOLOGIA CLÍNICA}

O que estamos chamando de Lebenswelt é, para Husserl (1970), o primeiro passo do movimento antinatural da consciência rumo a sua autoapresentação. É o reconhecimento de uma esfera que compreende a experiência ingênua na qual o sujeito "se entrega ao mundo, ao mundo que, enquanto horizonte universal está sempre aí consciente de um certo modo" (Husserl, 2012, p. 259). O Lebenswelt oferece ao fenomenólogo um modo de acesso à experiência antes da intromissão objetivista das ciências e sem a diferenciação entre sujeito e objeto, ou qualquer sorte de dicotomias. Na proposta de uma fenomenologia clínica, inspirada na releitura de Merleau-Ponty da fenomenologia husserliana e regida sob o conceito de Lebenswelt, o mundo da vida não é tratado como um meio auxiliar que se apoia no fluxo autoconstituinte da subjetividade transcendental, mas é ele mesmo o reduto do exercício subjetivo. Trata-se de uma clínica que se institui na ambiguidade da experiência do sujeito no mundo e no processo de significação que é indissociável do nosso enraizamento mundano.

Diferentemente de Husserl, Merleau-Ponty nos diz que não precisamos "colocar, atrás desse fluxo [aquele das intuições naturais produzidas no Lebenswelt], um outro fluxo para tomar consciência do primeiro", uma vez que ele "se constitui como fenômeno em si mesmo" (Merleau-Ponty, 2006, p. 571). Para Merleau-Ponty (1945/2006), que busca devolver a ambiguidade à problemática transcendental, o Lebenswelt, em sua esfera autossuficiente, dispensa um fluxo que corrija o aspecto ambíguo do exercício subjetivo.

Assim, a clínica do Lebenswelt é uma clínica da existência e, como tal, incorpora a dimensão do tempo como elemento constituinte da experiência. A verdade da subjetividade transcendental é a manutenção de uma lógica temporal que tensiona os pólos antagônicos do mundo objetivo, é a realização de uma experiência da ambiguidade como o estabelecimento da verdadeira subjetividade transcendental. De tal forma que nossa contribuição acerca da experiência ambígua do tempo se coloca no rumo de fornecer bases teóricas que possam dar conta de explicitar a subjetividade sem a utilização de recursos da redução objetivista, tampouco das psicologias da introspecção e nem mesmo das psicologias do inconsciente. A ideia de tempo serve para nos mostrar que a definição de subjetividade não precisa optar por polos antagônicos, mas pode se valer daquilo que a própria experiência revela de sua natureza.

A principal argumentação deste texto foi a de defesa de um sujeito que fosse, igualmente, o assentamento no passado, e uma projeção para o futuro. Assim, a clínica do Lebenswelt não necessita de uma forma subjetiva capaz de destruir a ambiguidade da experiência. Ela 
precisa afirmá-la no interior da clínica psicológica, ou seja, permitir o desvelamento e compreensão dos significados das experiências vividas do sujeito em seu horizonte temporal que, necessariamente e ambiguamente, o envolve como um todo.

Ao passo que o sujeito não é uma instância privada, porquanto aquele que tropeça na transcendência do tempo só pode formar sentidos internos, ele tampouco é uma forma reativa, estimulada por meios exteriores. Por esta razão, apoiado da transcendência do tempo, o sujeito pode utiliza-la como plataforma para produzir, no diálogo da subjetividade com a cultura, um sentido que lhe seja próprio, ou reconhecer em um sentido já sedimentado um importante reconhecimento, fora de si, de algo que revela sua própria vivência. A clínica busca alcançar esta trama temporal tecida por um sujeito, inserido no mundo, que em sua dimensão singular tece e retece suas experiências.

\section{CONSIDERAÇÕES FINAIS}

Em primeiro lugar, como vimos, a lógica do tempo é a de manter sob tensão as esferas dos eventos transcorridos e atuais e, talvez a mais importante, é a impossibilidade de uma superação integral de nossa ancestralidade pré-pessoal. A intersubjetividade é, portanto, uma forma de vivência que não pode ser entendida como uma maneira de ação capaz de corroer tudo aquilo que a antecede. O padrão da coerência interna do tempo é o de manter unidos, por um processo dialético sem síntese, sujeito e objeto, passado e futuro. Por isso, a temporalidade, quando empresta seu padrão lógico à subjetividade, não depura a contradição a partir da qual as sínteses parciais do tempo se desdobram.

Propomos neste artigo que a ideia da experiência do tempo como ambiguidade seja trazida diretamente para a fenomenologia clínica, seja na psicoterapia ou na intervenção terapêutica na psiquiatria ou na psicologia clínica. Trata-se de uma fecunda contribuição para a fenomenologia clínica em sua constante busca de compreensão da experiência do sujeito. A partir do princípio englobante do tempo, no qual o sujeito nem é inteiramente distinto, nem inteiramente igual ao objeto; nem inteiramente livre, nem inteiramente determinado pela biologia e pela cultura humana, a intersubjetividade pode ganhar uma nova forma de habitar a clínica psicológica.

$\mathrm{Na}$ perspectiva da fenomenologia clínica do Lebenswelt, defendemos a ideia de que, ao invés de se apresentar como um aspecto normativo da experiência subjetiva, possamos utilizar um método capaz de possi- bilitar que esta subjetividade emerja no campo clínico, na experiência intersubjetiva que lhe é própria. Assim, não é a despeito de uma ambiguidade que podemos testemunhar a projeção das narrativas humanas no futuro, ou seu recuo ao passado no tempo. Aqui, trata-se de assumir a dimensão transcendental do tempo na intersubjetividade. É exatamente por conta da ambiguidade entre o passado e futuro, entre o dado e o constituído, que o sujeito pode destacar-se do atual, num processo contínuo de apropriação e criação de sentidos.

\section{REFERÊNCIAS}

Barbaras, R. (2001). De l'être du phénomène. Sur l'ontologie de Merleau-Ponty, Paris : Vrin.

Bimbenet, E. (2011). L'animal que je ne suis plus. Paris: Gallimard.

Bimbenet, E. (2011) Quelques propositions merleau-pontiennes en psychiatrie phénoménologique. In E. Bimbenet, Après Merleau-Ponty. Études sur la fécondité d'une pensée (pp. 129-165), Paris: Vrin.

Binswanger, L. (2005). Melancolie et Manie. Paris: Presses Universitaires de France. (Trabalho original publicado em 1960).

Charbonneau, G. (2010) Introduction à la psychopathologie phénoménologique. Tome I. Paris, MJW Fédition.

Dastur. F. (2014). Penser ce qui advient. Dialogue avec Phillipe Cabestan. Paris : Les petits Platons, Coll. Les Dialogues de Petits Platons.

Dorfman, E. (2007). Réapprendre à voirle monde: MerleauPonty face au miroir lacanien. Springer: Netherlands.

Dupond, P. (2008) Dictionnaire Merleau-Ponty, Paris : Ellipses.

Coelho Jr., N. E. \& Carmo, P. S. (1991). Merleau-Ponty: filosofia como corpo e existência. São Paulo: Escuta.

Ferraz, M. (2006). O transcendental e o existente em Merleau-Ponty. São Paulo: Associação Editorial Humanitas.

Goldstein, K. (1995). The organism: a holistic approach to biology derived from pathological data in man. Zone books, New York.

Husserl, E. (1970). The crisis of European sciencies and transcendental phenomenology: an introduction to phenomenological philosophy (D. Carr, Trans). Evanston: NorthwesternUniversity Press. (Originalmente publicada em 1954).

Husserl, E. (1994). Lições para uma fenomenologia da consciência interna do tempo. Lisboa: Imprensa Nacional Casa da Moeda.

Leconte, P. (2012). Note sur la temporalité chez MerleauPonty. Philosopsis. pp. 1-18. Setembro. Retirado de http://www.philopsis.fr/IMG/pdf/temps-merleau-pontyleconte.pdf

Merleau-Ponty, M. (1964). The primacy of perception and its philosophical consequences. In: Edie, J (org). The primacy of perception and other essays in phenomenological 
psychology, the philosophy of art, history and politics. Northwestern University Press: Evanston.

Merleau-Ponty, M. (1973). Ciências do homem e fenomenologia. São Paulo: Saraiva.

Merleau-Ponty, M. (2006). A estrutura do comportamento (M. V. M. Aguiar, Trans). São Paulo: Martins Fontes. (originalmente publicado em 1942).

Merleau-Ponty, M. (2006). Fenomenologia da percepção (C. A. R. Moura, Trans). São Paulo: Martins Fontes. (originalmente publicado em 1945).

Merleau-Ponty, M. (2006). Psicologia e pedagogia da criança. São Paulo, Martins Fontes.

Minkowski, E. (1995). Le temps vecu. Paris: Presses Universitaires de France. (Trabalho original publicado em 1933)

Moura, C.A. R. (2008). Intencionalidade e existência: Husserl e Merleau-Ponty. In: Valverde, M. (org.). Merleauponty em Salvador. Salvador: Arcádia.

Moreira, V. (2007). De Carl Rogers a Merleau-Ponty: a pessoa mundana em psicoterapia. Annablume: São Paulo.

Moreira, V. (2009). Clínica humanista-fenomenológica: estudos em psicoterapia e psicopatologia crítica. Annablume: São Paulo.

Oliveira, M. A. (2012).Experiência originária e subjetividade transcendental em Husserl. In: Oliveira, M.A. Antropologia filosófica contemporânea: subjetividade e inversão teórica. São Paulo, Paulus.
Pinto, D. M. (2008). Interioridade, tempo e experiência: Merleau-Ponty e os limites da durée bergsoniana. In: Valverde, M. (org.). Merleau-Ponty em Salvador. Salvador: Arcádia.

Ricoeur, P. (1997). Tempo e narrativa. Tomo iii. Campinas: Papirus.

Strauss, E. (2000). Uma perspectiva existencial do tempo (J. N. G. de Araújo, Trad.). Revista Latinoamericana de Psicopatologia Fundamental, 3(3), 115-123. (Trabalho original publicado em 1968)

Tatossian, A. (1997/2014). Psychiatrie Phénoménologique. Paris: MJW Fédition.

Tatossian, A \& Moreira, V. (2012). Clínica do Lebenswelt: psicoterapia e psicopatologia fenomenológica. São Paulo: Escuta.

Waelhens, A. (2006). Uma filosofia da ambiguidade. In: Merleau-Ponty, M. A estrutura do comportamento. São Paulo: Martins Fontes.

\section{Notas:}

Recebido em: 07/2013 Primeira decisão editorial em: 04/2016

Aceito em: 08/2016

${ }^{1}$ Este artigo está vinculado ao projeto de produtividade em pesquisa PQ-2 - CNPq: Fenomenologia Clínica como Intervenção Terapêutica. Financiamento Edital 05/2016 Financiamento Complementar à Pesquisa - Universidade de Fortaleza - UNIFOR - projeto 1965) e ao projeto Saúde Mental, Psicologia e Fenomenologia: compreendendo a interlocução entre os campos de saber. Financiamento Edital 06/2016 Auxílio à pesquisa Jovens Pesquisadores - Universidade de Fortaleza - UNIFOR (projeto 2028). 